Article

\title{
Expanding and Embedding Digital Literacies: Transformative Agency in Education
}

\author{
Andreas Lund *, Anniken Furberg and Greta Björk Gudmundsdottir \\ Department of Teacher Education and School Research, University of Oslo, 0317 Oslo, Norway; \\ E-Mails: andreas.lund@ils.uio.no (A.L.), anniken.furberg@ils.uio.no (A.F.), g.b.gudmundsdottir@ils.uio.no (G.B.G.) \\ * Corresponding author
}

Submitted: 13 December 2018 | Accepted: 1 February 2019 | Published: 11 June 2019

\begin{abstract}
Socio-political, environmental, cultural, and digital changes require literacies that will be crucial for facing complex challenges. This article contributes to a notion of digital literacies as agentic and transformative and having epistemological implications. Although studies in digital literacies have examined diverse forms of understanding and relating to digitalization, we find that few studies have adopted a principled approach to transformative enactment of digital literacies. Our analytic focus is on how agents turn to digital (and other) resources when faced with problems in order to make them manageable. We conceptualize this notion of digital literacies by drawing on the Vygotskian principle of double stimulation. To demonstrate how agentic and transformative literacies appear in technology-rich learning environments, we make use of an empirical setting in which lower secondary school students and their teacher face a conundrum in a science project. We use this case as an empirical carrier of the conceptual and analytical framework employed. The analysis shows how the teacher enacts digital literacies in the design and orchestration of student activities in technology-rich learning environments where unforeseen issues occur, and how the collaborating students enact digital literacies by drawing on resources that enable them to resolve their insufficient understanding of a problem to reach insights that are shared with their peers.
\end{abstract}

\section{Keywords}

agency; digital literacies; double stimulation; education; transformation

\section{Issue}

This article is part of the issue "Critical Perspectives on Digital Literacies: Creating a Path Forward", edited by Hiller A. Spires (North Carolina State University, USA).

(C) 2019 by the authors; licensee Cogitatio (Lisbon, Portugal). This article is licensed under a Creative Commons Attribution 4.0 International License (CC BY).

\section{Introduction: The Need for a Transformative Stance}

In the face of deep and wide-ranging changessocio-political, environmental, cultural, and digitalidentifying key competencies that will be crucial for facing complex challenges is now a central topic in policymaking, education, and research (Csapó \& Funke, 2017). The present article expands on a conceptualization of digital literacies in an educational context. We apply an agentic perspective in order to act upon the world and not merely understand it, i.e. a transformative activist stance (Stetsenko, 2017). For example, Säljö (2010) shows how the rapidly multiplying digital information archives represent an expanding social memory that require performative competence to be put to relevant and productive use. However, this requires human competence in selecting information, juxtaposing it, and synthesizing it into situated and valid knowledge. Also, as digital resources increasingly take on cognitive functions (calculating, ordering, searching, assembling, systematizing, making decisions, etc.), cognition becomes distributed. The result is that our performative competence, i.e. not merely what we document but how we arrive at the results, conflates with our notion of learning. This development affects how we deal with fundamental epistemological issues (Kotzee, 2013). Thus, we 
further argue that an agentive stance towards digitalization is especially important in education. New teaching and learning opportunities and challenges arise as digital technologies become increasingly sophisticated, powerful, pervasive, and-therefore-transformative. This means that merely understanding digitalization is not enough; students and teachers must exercise informed agency to make digital technologies serve our interests.

Digital technologies make it possible to expand educational repertoires and break out of the status quo. This is not technological determinism, as transformation depends on human agency. In education, this entails designing agentive tasks and assignments that require students to take action in order to make sense and syntheses of multiple sources and representations. This is where mind and context fuse in new ways: sophisticated algorithms and coding (not in its restricted sense), together with robotics are increasingly taught even in primary school to foster understandings of technology in light of human and organizational values (see e.g. Scaradozzi, Sorbi, Pedale, Valzano, \& Vergine, 2015). Virtual worlds and augmented reality add to this development. But such artifacts require more than understanding; they require informed agency in order to put them to beneficial use, social as well as epistemic. These digital trends converge in the need for informed, agentive, and transformative literacies. Unless we enact such literacies, we risk becoming disenfranchised from many of our most important tasks in life and being reduced to passive observers of what others choose for us, whether it be big business, unethical politicians, or media outlets with their own agendas.

In the following, we pursue and build this argument for agentive digital literacies in education. As an empirical carrier of such a notion of digital literacies, we present and analyze a situation in a natural science classroom. The case aims to demonstrate how transformative agency is enacted when students encounter a complex problem and turn to diverse resources in order to resolve the problem situation. For explanatory power, we draw on cultural-historical conceptual and analytic frameworks, in particular, Vygotsky's (1978) principle of double stimulation. As this framework addresses transformation using cultural artifacts, we find it to be conducive to understanding, unpacking, and analyzing transformative agency that involves digital resources.

\section{Perspectives on Digital Literacies: From Skills towards Transformative Practices}

As an evolving concept, digital literacies is not clearly defined (Ilomäki, Paavola, Lakkala, \& Kantosalo, 2016). Whereas Tømte (2013, p. 76) describes it as a "moving target" which changes in line with emerging technologies and contexts, Aesaert, Vanderlinde, Tondeur and van Braak (2013, p. 143) talk about it as a "tangled ball of concepts" lacking a unified definition. Hatlevik, Gudmundsdottir and Loi (2015) prefer using competence instead of literacies or skills, as the term includes a broader understanding of the phenomenon. Moreover, Hatlevik, Throndsen, Loi and Gudmundsdottir (2018) present several studies and how they relate to these concepts as combinations of a prefix (such as media, information, digital) and a domain part (such as competence, skills, literacy). All the same, llomäki et al. (2016) found in their literature review that the most commonly used term was digital literacy, followed by digital competence, media literacy, multiliteracies, and new literacy.

Knobel and Lankshear (2006) introduced three aspects amounting to the plural "digital literacies": information, which is typically connected to the creation or communication of information; epistemic engagement with information, such as validating or deciding the reliability of the information; and, finally, a capacity or set of skills. Epistemic engagement involves changes in the phenomena we study, changes in our conceptions of knowledge and knowing, changes in ourselves as "knowers," and changes in the relative significance of types of knowing; that makes this study very relevant for ours, although it does not specifically address transformative agency. De Oliveira Nascimento and Knobel (2017), in their review of sociocultural digital literacies research within preservice teacher education, find "a recognizable subset of the larger field of digital literacy and education research" (p. 84). They focused on social practices and "not a checklist of proficiencies or competencies" (p. 68), a position we endorse. The authors' focus on social practices avoids a competence oriented approach which is often found in (digital) literacies. As Poyntz (2015) also argues when critiquing this 'tools' and 'doing' approach, literacy is very much about thinking and analyzing using concepts, i.e. epistemic practices.

Across the diverse concepts, we find a development from the 1970s, when greater focus was on technological or tool-oriented definitions such as "computer" and "internet" literacy and towards a broader notion of digital literacies as enacted practice(s). Also, digital literacies and equivalent terms seem to constitute a complexity of concepts determined by regional differences, theoretical positioning, or disciplines. To summarize the research angle, we see conceptual development away from skills and tool orientation to a broader understanding of literacies, including epistemic aspects. However, there are epistemological implications in digital literacies which remain to be pursued; under what conditions we engage in epistemic work and how we come to knowledge is changing.

Policy-driven studies are important because they seek to operationalize and standardize results from research on digital literacies. Often, they apply items measuring digital literacies; for example, various large-scale studies, such as ICILS, PISA, PIAAC, PIRLS, TIMSS, and Eurydice, they include indicators on ICT proficiency in education, digital competence, and/or development of digital literacies. These studies monitor and compare extensive data sets on technology integration, access, and use in education. But as Hadziristic (2017, p. 13) argues in her 
overview of the development: "[there] is no single measure of digital literacy, and large studies like the OECD's PIAAC are imperfect indicators of the same."

Ottestad and Gudmundsdottir (2018) write that the early phases of ICT integration and digital literacy in education often focused on tool-related skills taught within a single subject. With the advent of the Internet in the early 1990s, however, national governments began to develop policies for ICT as a tool for expanding learning (BECTA, 1998; Plomp, Anderson, Law, \& Quale, 2009), i.e. a more pedagogical approach. This brought about several initiatives. Within the European Union, an emphasis on knowledge, skills, and competencies has emerged in the indicators used to measure digital literacies. Such development is evident in the DigComp competency framework (Carretero, Vuorikari, \& Punie, 2017; Ferrari, 2013). From a policy perspective, we can also notice an interesting shift in the Digital Education Action Plan (European Commission, 2018a), a key EU policy document. The focus shifts from access to infrastructure and devices to integration in education and innovation policies, "ensuring that technologies augment and improve, rather than just replace learning in and outside the classroom and the teacher's ability to do so" (European Commission, 2018b, p. 6).

As in the research literature, we see an emphasis from technical aspects to a more process-oriented approach. There has, for example, been a great focus on the availability of digital resources in schools as an indicator in large-scale studies. This is, for example, a part of the IEA studies SITES Module 1 (Pelgrum \& Anderson, 1999), SITES 2006 (Law, Pelgrum, \& Plomp, 2008), and ICILS 2013 (Fraillon, Ainley, Schulz, Friedman, \& Gebhardt, 2014), and can also be seen in the OECD PISA studies from 2006 onwards (OECD, 2006, 2010, 2014, 2016). The studies thus mirror investment and integration of ICT in schools, but they reflect less pedagogical aspects, curriculum integration, and what digital literacy entails for today's teacher and learner.

In the discussions on digital literacy, we also find critical voices. Partly, criticism has been leveled against the notion of young people as 'digital natives' that are inevitably socialized into multitasking and against educational designs that assume the presence of such capacity. For example, Kirschner and De Bruyckere (2017) argue that such capacities do not exist and that an uncritical perspective on digital literacy is detrimental to education. Another common criticism disapproves of digital literacies for being a too romantic or a simplistic panacea for enacting authentic, interactive, and collaborative learning (Burton, Summers, Lawrence, Noble, \& Gibbings, 2015). Similarly, Rachael Shapiro (2015) offers a comprehensive analysis of the rhetoric of digital literacies and a critique of "digital literacies and their technologies...portrayed as inherently democratic for individuals and nations and are promised to deliver economic competitiveness to those who can attain and best leverage them" (p. i).
These three critical voices serve to demonstrate that the term digital literacies is employed across several levels and domains and that they converge in their efforts to instill some realism in an often romantic or even euphoric rhetoric. We share this concern but emphasize that our mission in this article is not to promote digital literacies as a magic potion. The aim of the present article is to conceptualize and operationalize digital literacies by emphasizing a transformative and agentic stance in order to take on problem situations and where digital sources must be considered for breaking out of such situations.

Summing up, both key research and policy-driven studies on digital literacy show a development from skills and technological orientation to a wider literacy/competence orientation, attitudes, knowledge, and transformation. However, the use of the concept itself remains uncertain and ambiguous, and only to a limited extent highlighting the transformative and agentic aspect of students and teachers.

Based on current trends in digitalization and influential literature on digital literacies, we address the following research question:

- How are digital literacies conceptualized and enacted as an agentive transformative practice in a technology-rich educational setting?

\section{An Agentive and Transformative Conceptual Framework}

A conceptual framework and theoretical perspective provide a language and-consequently-insights that travel beyond the immediate and the local experience. Thus, a relevant theoretical perspective will have explanatory power beyond single instances of a phenomenon. We draw on Vygotskian perspectives and, in particular, transformative agency (Sannino \& Engeström, 2017; Stetsenko, 2017; Vygotsky, 1978) examined through Vygotsky's principles of double stimulation (see the section on methodology). These perspectives and analytical constructs address learning as transformation involving reciprocity between the individual and the collective, agents, and context, using cultural tools (linguistic, symbolic, material) as mediating artifacts for transformative purposes.

Recently, we have seen a rapidly accumulating body of studies on agency and transformative agency (see e.g. Emirbayer \& Miche, 1998; Etelepälto, Vähäsantanen, Hökkä, \& Paloniemi, 2013; Mäkitalo, 2016; Virkkunen, 2006, for essential contributions). These studies share a focus on agency as a multifarious endeavor, on a scale from resistance to committed change-making. In their seminal article on agency, Emirbayer and Miche (1998) posit that "something must be done-some practical judgment arrived at - that will render the given situation unproblematic, settled, and resolved" (p. 998). This position is further refined by Virkkunen (2006) in his asser- 
tion that "agency here means breaking away from the given frame of action and taking the initiative to transform it" (p. 49). The same applies to Mäkitalo (2016) when she identifies agency as "the capacity of humans to distance themselves from their immediate surroundings and...to intervene in, and transform the meaning of, situated activities" (p. 64, emphasis in the original). In these citations, agency and transformation are linked. Also, transformative agency is identified when agents experience a problem situation, show initiative to break away, and utilize available resources which may alleviate or resolve the problem situation. Such contextual resources increasingly emerge as sophisticated, complex, powerful, omnipresent, and pervasive digital resources.

But this takes us further into epistemologies of digital literacies. Our focus is on knowing how more than knowing what, but we acknowledge that the two cannot really be separated. Epistemic practices are closely intertwined with the educational discipline in question, which is also shown in our empirical case. When Maton (2013) sets out to enable "knowledge processes to be seen, their organizing principles to be conceptualized, and their effects to be explored" (p. 3), he aims to suspend what is frequently perceived as a dichotomy between knowing and knowledge, between subjectively constructed and absolute or universal knowledge. As our purpose is to demonstrate the value of transformative agency as an essential dimension of digital literacies, we place ourselves in a position where our concern is how we come to knowledge, mediated by resources that themselves have been instilled with certain epistemological intentions or even prescriptions. Wikis, for example, do not make much sense in a strictly individual perspective as it builds on a premise of shared authorship and everyone's privilege to add, delete and revise the text under construction. As we search for structures or underlying principles for a particular epistemic practice we reject relativism without endorsing absolutism; (new) knowledge exercises influence on the knower (see also Maton, 2007). In the present study, the implication is that we do not explicitly focus on learning effects or measurable outcomes of the epistemic work we analyze, although these could be pursued in further studies. Rather, we focus on how the students and their teacher enact epistemic work when facing a demanding learning task which requires extensive use of various artifacts.

When we link these brief reflections on epistemological positions to digital literacies, some questions become essential: Where is agency located? Is it exclusively a human quality, or is it distributed between humans and non-humans? If so, to what extent? The answer is not given in light of recent development in, e.g., robotics, augmented reality, and healthcare chips. Our position is that agency is not an innate disposition in the individual; it is developed in artifact-mediated and object-oriented interaction. While we need to be aware of different approaches to the relationship between human and nonhuman agents, our position is that agency is distributed across agents and artifacts, although the former is ontologically prioritized.

Extended cognition is perhaps the more conventional way of thinking about digitalization: how pocket calculators, spell checkers, smartphones, and a plethora of sophisticated artifacts have increasingly taken on more cognitive load and serve to engage with humans in distributed cognition (Hutchins, 1995). One challenge for schooling is that such artifacts blur or disguise at least part of students' cognitive work. Thus, extended and distributed cognition shifts the focus from merely presenting answers and solutions to epistemic practices that reveal how students arrive at certain solutions and answers among several possible alternatives (Säljö, 2010). In the case we present, students need to scientifically and conceptually understand a complex phenomenon, "trait heritability". Their epistemic work involves the agentive use of digital resources which carry epistemic work instilled in these resources by others. Thus, extended cognition materializing in digital resources mediates the students' epistemic journey from confusion to understanding.

Digital technologies also play a vital role when we design new educational spaces and workplaces, both physical and virtual. Digitalization becomes increasingly embedded in educational and scientific practices to the extent that it is ubiquitous but invisible. The consequence is that we as social agents also become increasingly embedded in practices, situations, and spaces permeated by digitalization. Thus, digital technologies also structure our cognition (Huebner, 2013) as we aim to demonstrate in this case when the students make use of digital resources. Also, the teacher in the case enacts digital literacies, not as mere technological skills, but by designing learning environments and trajectories where digital resources (collaborative, representational, etc.) are potentially conducive to students' knowledge advancement. So, a second principle of digital epistemology is its embeddedness; we as cognizant beings are embedded in knowledge instilled environments and knowledge instilled artifacts are increasingly embedded in our every day and epistemic activities.

An intriguing discussion on digitalization becoming embodied has also emerged (e.g. L. Shapiro, 2007). This will obviously have implications for a broader notion of digital literacies and epistemologies, although it does not sufficiently pertain to the present argument or case to pursue this highly complex and often controversial topic. However, we acknowledge that digital technologies "inhabit" our horizon of possibilities for action. This is highly relevant for agentic and transformative literacies.

In sum, we argue that we increasingly come to knowledge by engaging in extended, embedded, (and embodied) cognition. We further argue that such perspectives contribute to understanding as well as operationalizing an agentive and transformative stance towards digital literacies in a world where digital complexity is rapidly increasing and calls for informed human response and action. However, this argument is based on epistemically 
justified assumptions, i.e. epistemic humility (Matthews, 2006) and not a claim for epistemic accuracy.

We have sought to establish a conceptual framework that connects agentic, transformative literacies to epistemological implications of digitalization. Next, we turn to methodology in order to establish an analytical framework to be used in a case where we study students' and a teacher's interactions as they encounter a problem while studying genetics.

\section{Methodology: Interaction Analysis and Double Stimulation}

This case was selected since it makes important principles visible without being "atypical." Also, the case demonstrates that digital literacies come situated and with subject-specific features. Consequently, we argue that, although not statistically generalizable, the case serves as an empirical carrier of the reasoned judgment and operational logic for an agentive and transformative digital literacy that constitutes analytical generalization, i.e., "the extent to which findings from one study can be used as a guide to what might occur in another situation" (Kvale, 1996, p. 233). Thus, theorizing digital literacies in light of transformative agency does not emerge inductively but, on the other hand, neither is the case merely an illustration.

The data in the present case study was produced during a science project about genetics, which took place in 11 school lessons (each 60-minutes) over the course of four weeks. The participants were one class of 38 lower secondary school students, aged $15-16$ years, and their science teacher. The data material consists of three hours of transcribed video recordings of one student group's interaction during a group activity where the students inquired into the topic of "trait heritability." During the project, laptops, tablets, interactive whiteboard, and smartphones were used by students and teachers. Frequently used digital resources involved Viten.no (a webresource developed specifically for natural science education), Cells, a computer program, Forskning.no (an online research resource), and web pages from The Norwegian Biotechnology Advisory Board. In addition, Wikipedia, the online Comprehensive Norwegian Dictionary and web pages for Statistics Norway were consulted on a regular basis. This can be seen as epistemic embeddedness referred to in Section 3. The school endorsed collaborative learning and student active learning. The teachers worked in teams of four preparing and designing lessons. The teacher in the current case had degrees in math and biology and had 11 years of teaching experience. The learning activities in the project alternated between lectures, individual and group work on tasks, and the summarizing and consolidation of knowledge. In the first lesson, the students' prior knowledge was mobilized. This, together with the fact that the teacher exercised considerable disciplinary and pedagogic expertise and presence, rendered this particular inquiry-based teach- ing and learning activity immune from the sometimes scathing criticism of 'minimal guidance' models (see e.g. Kirschner, Sweller, \& Clark, 2006).

Video data enables us to examine the details of the students' interactions in group work settings as they take place in situ. We draw on interaction analysis to explore collaborative learning activities in technologyrich settings and show how the teacher dealt with challenges experienced by the students. The analysis of interactions during the selected episodes is the basis from which we demonstrate our conceptualization of transformative agency. We analyze two interaction sequences taking place during the group activity: one excerpt from a group setting where the students were working on their own, searching for relevant Web-based information, and one excerpt from the same setting also involving the teacher. Interaction analysis implies that talk and interaction between interlocutors as well as between interlocutors and artifacts are analyzed sequentially (Furberg, 2016; Jordan \& Henderson, 1995). Each utterance and action in a selected sequence is understood and seen in relation to the previous utterance and/or action in unfolding interactions. Analytical descriptions are oriented toward interactional achievements and not what might be taking place in individuals' minds (Linell, 2009).

To capture transformative agency in interactions, we make use of a set of analytical concepts adopted from Vygotsky's (1978) principle of "double stimulation" (the use of the term "stimulus" should not be understood in behaviorist terms). The essence can be summarized as follows: Stimulus 1 (S1) refers to a problem situation where agents encounter alternatives, double binds, impasses, conflicting motives, etc. However, unless the situation is alleviated or resolved, the agent is stuck, and the situation deteriorates further. Finding the unknown and decision making under uncertainty are examples. For instance, Silseth (2013) showed how senior high school students working with the computer game Global Conflicts: Palestine enacted agency for potential problem solving in a situation with incomplete and unreliable information.

To transform or break out of S1, agents must exercise transformative agency. This is where a series of second stimuli (S2) become relevant. Second stimuli may be social (e.g. peers, teachers), discursive (e.g. concepts, metaphors), symbolic (diverse representations), or material (e.g. laptops, software). The material S2 resources that agents invoke to break out of problem situations are increasingly digitalized and require diverse types of human agency. This is where the epistemological aspects of digital literacies emerge, but not necessarily immediately perceived aspects. Efforts to transform S1 may be successful or not, but either way, the invoked resources will feedback to the problem situation and alter its premises. In this process, the agent is also changed as s/he gains insights about S1 (Sannino \& Engeström, 2017; Lund \& Vest $\varnothing \mathrm{l}$, in press). These principles will be put to work in the empirical analysis of the case we present. 


\section{Enacting Digital Literacies: An Empirical Case}

Teaching is a profession where enacting digital literacies involve a dual focus; teachers must design technologyrich learning environments and trajectories, and, these must be conducive to their pupils' development of digital literacies as knowledge advancement, i.e. digital literacies are immersed in epistemic work. Teachers' intended designs become appropriated and transformed in class depending on the interactional rhythm and everchanging goals and purposes enacted there (Lund \& Hauge, 2011). In the case we present, there was no intention of enacting or fostering digital literacies as a competence per se. Rather, the enactment of digital literacies emerged in the embedded and extended epistemic relationship between actors and artifacts, the design and staging of the project and the lessons.

In science education, there has been increasing use of digital learning resources. This includes text-based resources and visual learning resources such as simulations, models, animations, and graphs aimed at supporting students' conceptual understanding and their development of epistemic skills. An example is resources designed for supporting 'inquiry learning', which entails developing hypotheses, carrying out experiments, and collecting and processing data (van Joolingen, de Jong, \& Dimitrakopoulou, 2007). Thus, we see learning environments where students need to be agentic because digital resources become extensions of the students' cognitive and epistemic work. But these resources are also embedded in students' learning situations and learning environments, while students and teachers are also embedded in a digitalized learning environment.

Several studies have shown that learning situations where the students utilize digital information resources can help support their conceptual understanding and epistemic work (Strømme \& Furberg, 2015). But studies also show that students experience challenges such as determining the quality and trustworthiness of Web resources, connecting epistemic work with conceptual knowledge, and transferring acquired conceptual understandings from one setting to another (van Joolingen et al., 2007). This amounts to-in Vygotskian termsa first stimulus (S1) or a problem situation (Vygotsky, 1978). The digital (and analog) resources referred to above represent a series of $\mathrm{S2}$, i.e. material artifacts students (and teachers) can utilize to break out of S1. This requires agentive digital literacies. The teacher contributes by mobilizing students' prior knowledge, clarifying terms and concepts, helping students articulate their ideas, and introducing entire classes to exercises and relevant resources that consolidate the different stages of a scientific study (Strømme \& Furberg, 2015). Thus, the teacher can be seen as a 'social S2' for the students; there is direct instruction but also a responsive, enabling, and structuring approach to teaching.

In the events described below, the students and the teacher looked into the topic "trait heritability." In his preceding lecture, the teacher explained the concept "genetic dominance" and how, using a Punnett square diagram, one can calculate the likelihood of inheriting particular traits such as gender. He had prepared a PowerPoint presentation emphasizing keywords as well as a number of visualizations. Thus, we see how the teacher as a designer prepares a series of S2 for the students to help them transform a situation in which they encounter a difficult phenomenon in genetics (S1). To illustrate how to construct a Punnett square diagram to calculate trait heritability, the teacher used a diagram from a textbook showing the genetic variations of blackfurred rabbits (cf. Figure 1).

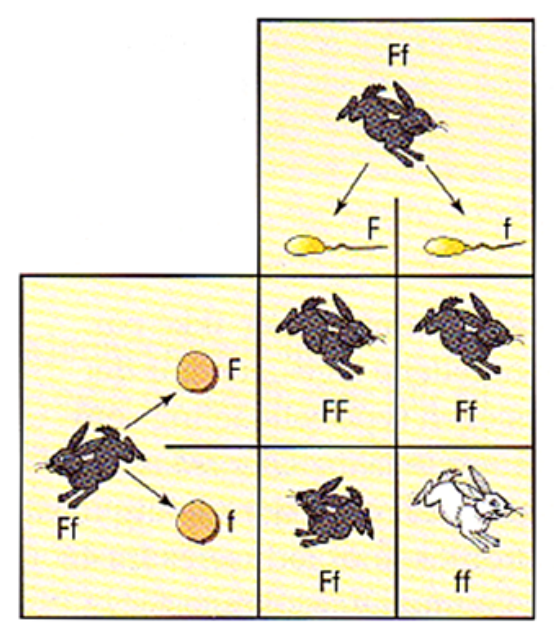

Figure 1. Punnett square diagram for two black-furred rabbits, as shown by the teacher.

After the introductory lecture, the students worked in groups to draw up a Punnett square diagram to calculate probabilities related to eye color and gender. The groups used iPads, PCs, and their smartphones, i.e. digital extensions of their cognitive and epistemic efforts, to search for relevant information regarding the Punnett square diagram. The teacher also provided them with a list of online links. Thus, we see how technologies are embedded in student work and how students are embedded in technology-rich learning environments. Below, we present two excerpts of conversations which took place right after the whole-class discussion. During the ensuing 20 minutes, the students worked in groups. Students named Gunnar, Tine, and Hans were involved in making a Punnett square diagram to calculate the probability of gender.

The students sit around a table with the textbook, a copy of two pages from another textbook, an iPad, and a cellphone that belonged to one of the students (cf. Figure 2). In addition, they have their personal notebooks. Hans finds an online statistics article that presented an overview of the number of females and males born during the last decade. The statistics showed a 51.3 percent chance of the firstborn being male. The students put aside the article for a moment to grapple with the Punnett square diagram. 

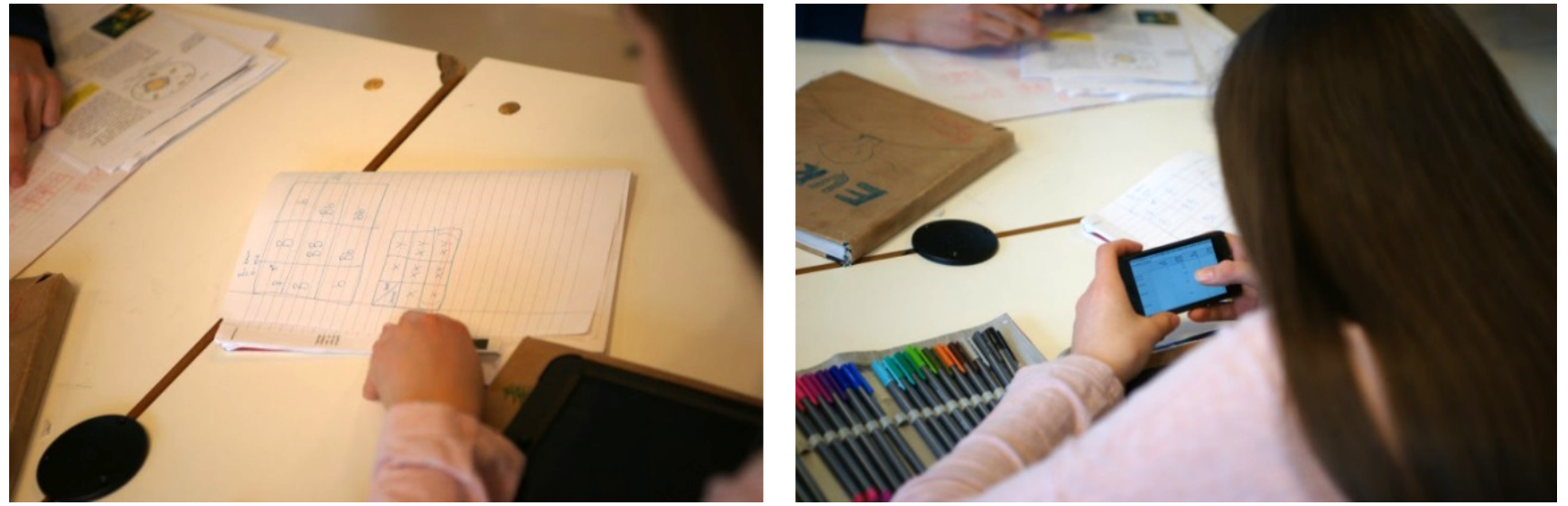

Figure 2. Pictures of the students working with the Punnett square diagram.

Excerpt 1. Dealing with divergent statistics.

\section{Excerpt 1}

1. Gunnar: For girls, there will always be $\mathrm{X}$, 'cause they've got $\mathrm{XX}$, so if you divide it in half, it will still be $\mathrm{X}$. While with boys, it's XY, and so it's random which of them it will be

2. Tine: Okay, then we just have to draw it up, huh

3. Gunnar: You don't need more than $\mathrm{X}$ on one side, and $\mathrm{XY}$ for boys. And then, right away, it's $\mathrm{X}$ and $\mathrm{X}$ and $\mathrm{X} \mathrm{Y}$. $50 \%$

4. Tine: $50 / 50$. Girl is $X$ and boys are $X Y$ (.) But uhm, then I don't get why there isn't a bigger chance for it to be a girl (.) XX and XX XY and XY (2)

5. Gunnar: There's a caption above some tables, see

6. Hans: Yeah

7. Gunnar: It's difficult to say, but it's (.) that means that there are a teeny bit more-- That's almost an insignificant difference. So it's almost coincidental

8. Hans: 51. Look ((points to the table)) (2) Everything relies on a 51-ish chance for boy

9. Camilla: Norwegian Children... boy.. Is that the table=

10. Georg: If you scroll down... it's from Statistics Norway, isn't it?

11. Tine: It is. Firstborn, thirdborn. But, then there's always a bigger chance of getting a boy, isn't there?

12. Gunnar: Yeah, that's a bit strange(.) Maybe it's written (.) err. It has something to do with how many brothers and sisters-- It's a little difficult, I don't really understand it. What makes it not be exactly $50 \%$ ?

The opening of Excerpt 1 shows that when the students discover the divergence between the statistics they found online showing a 51.3 percent chance of having a boy and the Punnet diagram where they ended up with a 50 percent chance, they decide to revisit their diagram and check whether they have got it right (lines 1-4). Tine's utterance, "I don't get why there isn't a bigger chance for it to be a girl" (line 4) indicates that she is puzzled by their discovery. Hans and Gunnar add that they also find this strange. In line 10 Georg asks, "it's from Statistics Norway, isn't it?", indicating that he wants to make sure that this is a reliable source. The students continue to discuss various reasons for the differences in childbirth probabilities until Gunnar concludes; "I don't really understand it. What makes it not be exactly $50 \%$ ?" (line 12). At this point, it is clear that the students do not know how to resolve the discrepancy.

The interaction among the students shows what happened when the students encountered information that went beyond the examples presented by both the teacher and the textbook, both of which stated there being a 50/50 probability of giving birth to a male or female child. The confusion articulated by the students amounted to a typical instance of a problem situationan S1-where contradictory explanations appeared to place the students at an impasse. Without mobilizing (a series) of potentially emancipating resources (S2) the students would remain stuck and might give up. Hans's introduction of the online statistics (turn 8) emerged as such a potential S2. Epistemologically, the episode dis- 
played in Excerpt 1 also serves to show how digitalization serves as extended and distributed cognition; the online data they found was appropriated by students in their epistemic efforts. The way out of the problem situation was not found solely through the use of their minds.

In Excerpt 2 we enter the setting in which the students have summoned the teacher in order to ask him about the article they have found.

Tine shows the teacher the article and the statistics they have found (line 1), and Hans explains that according to the table there is a slightly bigger chance of giving birth to "a boy" (line 2). The teacher looks at the table, and consent to the students' discovery. Then he adds: "Why is that?" (line 7). Tine, followed by Hans, suggest that the Punnett is a simplification (lines 8 and 10) of a more complex phenomenon. The teacher confirms this. Then he encourages the students to find information that could help explain why there is a greater chance of giving birth to males. Motivated by the teacher's encouragement, the students decide to follow up on their discovery, and begin their search for information that could shed light on this issue. Searching the internet, they discover a web article that puts forward a hypothesis stating that the higher frequency of male births may be due to disparities in the swimming speed of the spermatozoa. In the ensuing whole-class discussion, the teacher asks the students to share their findings with the rest of the class.
This agentive and transformative approach is linked to the use of diverse resources, resulting in the students gradually breaking out of the initial S1. The Punnett diagram proved to be an inadequate S2 having insufficient explanatory power whereas the online article proved to be a new and more advanced S2. Also, the teacher's subtle assistance shows how he orchestrated the unfolding inquiry by pointing to peers and resources. His question in turn 11 and his final words in the excerpt, "something isn't quite right here," spurred the students to move on with their inquiry and triggered their agentive stance. The teacher did not interrupt a learning opportunity by providing a direct answer to Tine (turn 16). It was left to the students to further transform their epistemic status by searching for, appropriating, and using relevant online information in order to break out of a situation that threatened to stifle them.

\section{Discussion: Students and Teacher with Transformative Agency}

Initially, we asked How are digital literacies conceptualized and enacted as an agentive transformative practice in a technology-rich educational setting? In the following, we systematize our interpretations in two sections: the first involving the students and the second involving the teacher. This is not because digital literacies appear

Excerpt 2. Dealing with simplification and complexity.

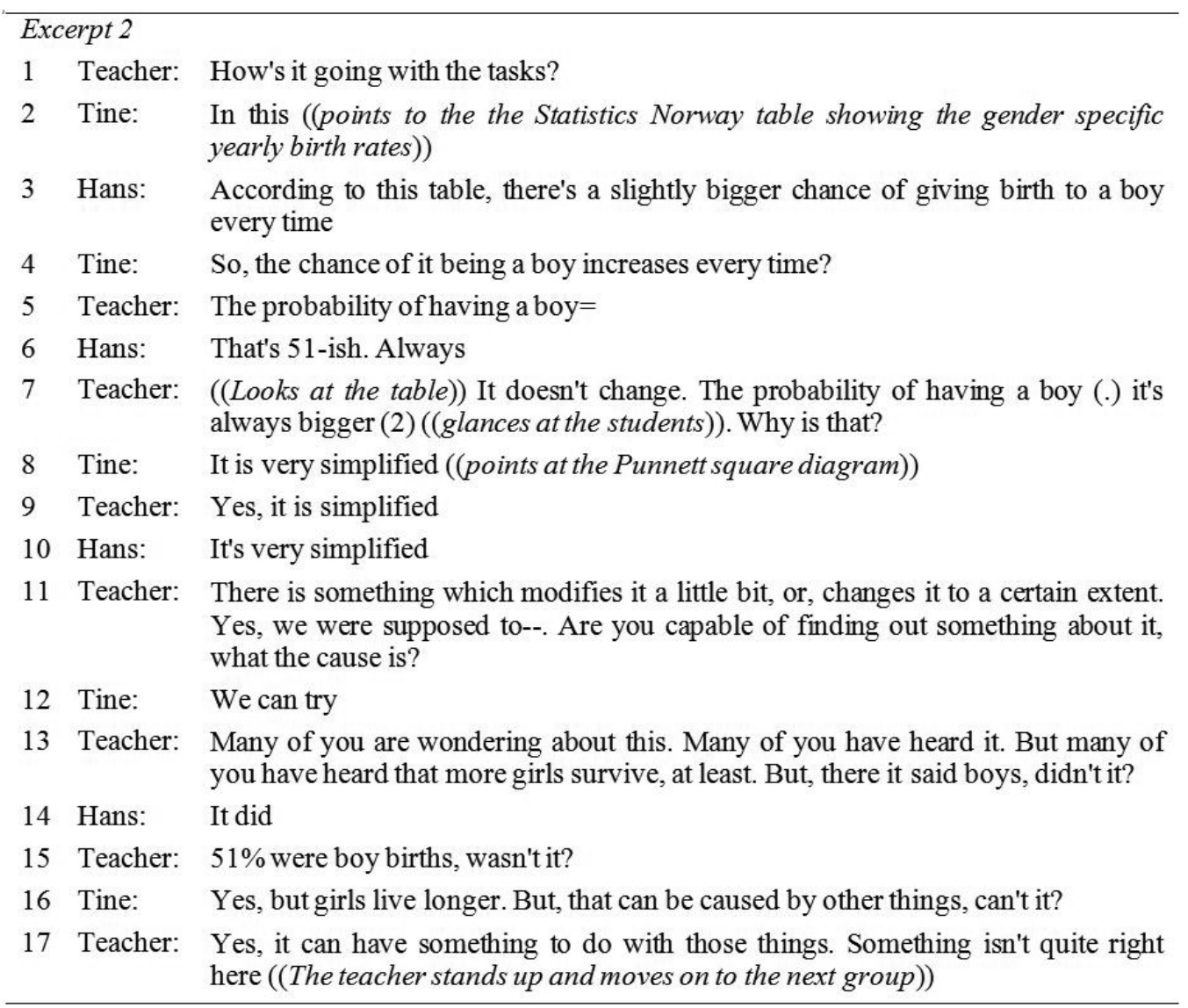


as fundamentally different from the two types of agents, but because they are situated and engaged in different practices: learning and teaching.

\subsection{Transformative Agency as a Vital Dimension of Students' Digital Literacies}

As for the students, we emphasize four aspects of digital literacies in the case. First, activating digital resources has no value in itself; it must be connected to a problem situation. For the students, understanding a complex phenomenon in genetics proved to be such a problem situation (S1). An early indication of agency is when students start considering resources, given or actively sought, analog or digital, in order to break out of or transform S1. This is a recognition that something must be done, in this case involving digital literacies as one of several potentially relevant social practices. We see a concerted effort in the sense that the students gradually explored diverse resources: analog, digital, social, and conceptual.

Secondly, students find themselves embedded in available resources. At this stage, digital resources become more distinct as they provide access to infinite sources of information, respond immediately, allow for copying and sharing, and suspend constraints in space and time. We have referred to this as technologies being embedded in learning environments and agents being embedded in digitalized environments. Again, this calls for an agentive stance towards digitalization: what seems relevant, what can it offer, how do I/we utilize its affordances, etc. This is where digital literacies mean connecting the problem situation and the available digital resources in order to transform the situation. In our case, we saw how students were faced with a conundrum when they realized the discrepancy in explanatory power between the analog Punnett square diagram and the digital resources.

Thirdly, some resources proved to be more conducive to epistemic transformation than others. This is a result of informed navigation and selection but also social interaction with peers and the teacher. Furthermore, this transformational aspect did not merely remain with the group at work; it was shared with the class. At this stage, the students in the group had transformed the original problem situation, S1, into a situation where they were actually able to share their newfound insight. Thus, the case demonstrates development at very close range and also reveals how digital literacies require a distinct agentic aspect in order to bring about learning.

Finally, as the case serves to open a particular situation in order to unpack its dynamics it does not yield data to claim lasting transformation of agents, learning outcomes or extended epistemic horizon beyond the local situation. However, the analysis of the students' work with a series of S2 in order to transform S1 indicates that this dynamic and dialectic approach to problem solving can connect agentive digital literacies to documented learning effects.

\subsection{Transformative Agency as a Vital Dimension of the} Teacher's Digital Literacies

As for the teacher, there are four aspects of the case that we wish to draw attention to and examine in light of teachers' digital literacies. One aspect concerns the possibilities which arise in situations where students and teachers utilize multiple information sources. The excerpts demonstrate what can occur in situations where students encounter different perspectives or conflicting explanations for the same phenomenon and how the teacher mediates navigation and orchestration of student activities in this learning environment. We have pointed to the teacher as a designer of technology-rich learning environments, but without necessarily being an expert in digital literacies, enacted as skills. This resonates with Andrews and McDougall's (2012) 'pedagogy of the inexpert'; "a handing over of power, of mastery, towards a more negotiated pedagogy" (p. 154) in situations where the plethora of resources bring about "assemblage events" (p. 158).

A second aspect concerns the way the teacher used the situation as a point of departure to motivate the students in their search for knowledge. The teacher did this by recognizing the relevance of the conflicting information found by the students. However, instead of giving the students the answer, he encouraged them to resolve the quandary by searching for additional information online.

A third aspect is related to designing learning environments with various forms of knowledge representations, e.g. online statistical information and visual representations (the Punnett square diagram). Thus, the teacher needed to adapt his planned lesson to his students' new findings. The case is an example of what several studies show: that navigating diverse forms of knowledge representations can help improve the students' grasp of the subject matter (Furberg, 2016). Also, we see that digital literacies are seldom enacted as a separate practice but are intertwined with the use of multiple analog, conceptual, symbolic, and social resources.

Historically, the textbook and the teacher's explanations were considered as authoritative information sources. However, the bringing in of information from other sources can weaken this authority. The teacher dared to let go of his authority and encourage the students to advance their understanding by finding additional relevant information online. The case also shows that digital literacies involve the need for knowledge about subject representations and the ability to facilitate the use of an exploratory method that draws on digital resources. Finally, the case shows that digital literacies are also about being able to deal with unpredictable, complex, and explorative teaching and learning situations. We have argued that this connects with an epistemology where we come to knowledge through extended and embedded (and, increasingly, embodied) cognition. As digital resources suspend constraints in time and space, link 
hands and minds to infinite information, and suspend the gap between mind and context, digital literacies have become interwoven with digital epistemologies.

\section{Conclusion}

In this article, we have argued for a notion of digital literacies as taking an agentive and transformative stance towards digitalization, not in order to replace other notions of digital literacy but to emphasize a dimension which we argue is a contribution to the field. We have applied the dynamic relationship between problem situations (S1) and diverse potential resources (S2), such that $\mathrm{S} 2$ can be activated in order for agents to transform and break out of the original S1. This is essential for an understanding of digital literacies as a social and epistemic practice that is intertwined with other forms of literacy and which requires an agentic and transformative approach. By applying the Vygotskian (1978) principle of double stimulation, we revealed how students and a teacher exercised transformative agency when faced with a problem situation and transformed it into a learning experience, very much by enacting agentive digital literacies. The rationale for this approach is found partly in the extremely rapid and dramatic development of digital technologies and partly in highly relevant socio-political scenarios we have only hinted at, and particularly in the epistemological implications we identify. We have limited ourselves to an educational context, since this connects our conceptual arguments to the analysis of an empirical case from a class.

There are implications for educational practice and research. As for practice, we find that an agentive and transformative approach to digital literacies has consequences for task design in education. Tasks that can be fulfilled by providing a "correct" answer do not match the socio-political and technological development we have briefly outlined. Students need to address openended tasks and fuzzy problems which lend themselves to collaborative inquiry, both afforded and mediated by increasingly sophisticated digital resources. However, this requires the kind of agentive literacies demonstrated by the students in our empirical case. As for the teacher, $s /$ he becomes a designer of an educational sequence and assemblage of events where such tasks and available digital resources are aligned with students' modes of work (individual, group, online, etc.) and-in turn-new assessment criteria and practices.

As for educational research, we argue that there is considerable untapped potential in applying and refining the Vygotskian (1978) principle of double stimulation. In the case presented here, we have confined our study to unpacking a situation in order to reveal an underlying principle of transformative agency. This principle emerges as a dynamic and dialectic unit of analysis (Lund \& Vestøl, in press) and makes it possible to analyze transformation or instigate transformative interventions on a scientific basis. Also, future studies should be longitudinal and expand the focus to more clearly identify learning outcomes from transforming the problem situation (S1). We realize that such endeavors-whether in practice or research-may appear daunting, but no more so than understanding what learning in a digitalized society involves.

\section{Acknowledgments}

The empirical case is based on data from the Ark\&App project funded by the Norwegian Directorate for Education and Training, and the Department of Teacher Education and School Research, University of Oslo.

\section{Conflict of Interests}

The authors declare no conflict of interests.

\section{References}

Aesaert, K., Vanderlinde, R., Tondeur, J., \& van Braak, J. (2013). The content of educational technology curricula: A cross-curricular state of the art. Educational Technology Research and Development, 61(1), 131-151.

Andrews, B., \& McDougall, J. (2012). Curation pedagogy for media studies: (Further) towards the inexpert. Medijske Studije/Media Studies, 3(6), 152-166.

BECTA. (1998). How learning is changing: Information and communications technology across Europe. ICT in education policy. Coventry: BECTA.

Burton, L. J., Summers, J., Lawrence, J., Noble, K., \& Gibbings, P. (2015). Digital literacy in higher education: The rhetoric and the reality. In M. K. Harmes, H. Huijser \& P. A. Danaher (Eds.), Myths in education, learning and teaching (pp. 151-172). London: Palgrave Macmillan.

Carretero, S., Vuorikari, R., \& Punie, Y. (2017). DigComp 2.1: The digital competence framework for citizens with eight proficiency levels and examples of use (No. JRC106281). Seville: JRC. https://doi.org/10. $2760 / 38842$

Csapó, B., \& Funke, J. (2017). The development and assessment of problem solving in 21st-century schools. Paris: OECD Publishing.

de Oliveira Nascimento, A. K., \& Knobel, M. (2017). What's to be learned? A review of sociocultural digital literacies research within pre-service teacher education. Nordic Journal of Digital Literacy, 12(3), 67-88. https://doi.org/10.1826/ISSN.1891-943X2017-03-03

Emirbayer, M., \& Miche, A. (1998). What is agency? American Journal of Sociology, 103(4), 962-1023.

Etelepälto, A., Vähäsantanen, K., Hökkä, P., \& Paloniemi, S. (2013). What is agency? Conceptualizing professional agency at work. Educational Research Review, 10, 45-65. http://dx.doi.org/10.1016/j.edurev.2013. 05.001

European Commission. (2018a). Digital education ac- 
tion plan. European Commission. Retrieved from https://ec.europa.eu/education/digital-educationaction-plan-action-10-artificial-intelligence-andanalytics_en

European Commission. (2018b). Communication from the Commission to the European Parliament, the Council, the European Economic and Social Committee and the Committee of the Regions (COM(2018) 22 final). Brussels: European Commission. Retrieved from https://eur-lex.europa.eu/legal-content/EN/ TXT/PDF/?uri=CELEX:52018SC0012\&from=EN

Ferrari, A. (2013). DIGCOMP: A framework for developing and understanding digital competence in Europe. Luxembourg: Publication Office of the European Union.

Fraillon, J., Ainley, J., Schulz, W., Friedman, T., \& Gebhardt, E. (2014). Preparing for life in a digital age. The IEA international computer and information literacy study. International report. Cham: Springer.

Furberg, A. (2016). Teacher support in computersupported lab work: Bridging the gap between lab experiments and students' conceptual understanding. International Journal of Computer-Supported Collaborative Learning, 11, 89-113.

Hadziristic, T. (2017). The state of digital literacy: A literature review. Toronto: Ryerson University, Brookfield Institute for Innovation and Entrepreneurship.

Hatlevik, O. E., Gudmundsdottir, G. B., \& Loi, M. (2015). Digital diversity among upper secondary students: A multilevel analysis of the relationship between cultural capital, self-efficacy, strategic use of information and digital competence. Computers \& Education, 81, 345-353.

Hatlevik, O. E., Throndsen, I., Loi, M., \& Gudmundsdottir, G. B. (2018). Students' ICT self-efficacy and computer and information literacy: Determinants and relationships. Computers \& Education, 118, 107-119. https://doi.org/10.1016/j.compedu.2017.11.011

Huebner, B. (2013). Socially embedded cognition. Cognitive Systems Research, 25/26, 13-18.

Hutchins, E. (1995). Cognition in the wild. Cambridge, MA: MIT Press.

Ilomäki, L., Paavola, S., Lakkala, M., \& Kantosalo, A. (2016). Digital competence: An emergent boundary concept for policy and educational research. Education and Information Technologies, 21(3), 655-679.

Jordan, B., \& Henderson, A. (1995). Interaction analysis: Foundations and practice. Journal of the Learning Sciences, 4(1), 39-103.

Kirschner, P., \& De Bruyckere, P. (2017). The myths of the digital native and the multitasker. Teaching and Teacher Education, 67, 135-142. http://dx.doi.org/ 10.1016/j.tate.2017.06.001

Kirschner, P. A., Sweller, J., \& Clark, R. E. (2006). Why minimal guidance during instruction does not work: An analysis of the failure of constructivist, discovery, problem-based, experiential, and inquiry-based teaching. Educational Psychologist, 41(2), 75-86.

Knobel, M., \& Lankshear, C. (2006). Digital literacy and digital literacies: Policy, pedagogy and research considerations for education. Nordic Journal of Digital Literacy, 1(1), 12-24.

Kotzee, B. (2013). Introduction: Education, social epistemology and virtue epistemology. Journal of Philosophy of Education, 47(2), 157-167.

Kvale, S. (1996). InterViews. Thousand Oaks, CA: SAGE.

Law, N., Pelgrum, W., \& Plomp, T. (Eds.). (2008). Pedagogy and ICT use in schools around the world: Findings from the IEA SITES 2006 study. CERC studies in comparative education. Dordrecht: Springer.

Linell, P. (2009). Rethinking language, mind, and world dialogically: Interactional and contextual theories of human sense-making. Charlotte, NC: Information Age Publishing.

Lund, A., \& Hauge, T. E. (2011). Designs for teaching and learning in technology rich learning environments. Nordic Journal of Digital Literacy, 6(4), 258-271.

Lund, A., \& Vestøl, J. M. (in press). Analytical units of transformative agency: Emergency and emergence. Learning, Culture and Social Interaction.

Mäkitalo, Å. (2016). On the notion of agency in studies of interaction and learning. Learning, Culture and Social Interaction, 10, 64-67. http://dx.doi.org/10.1016/j. Icsi.2016.07003

Maton, K. (2007). Knowledge-knower structures in intellectual and educational fields. In F. Christie \& J. R. Martin (Eds.), Language, Knowledge and pedagogy. Functional Linguistic and Sociological Perspectives. London and New York, NY: Continuum.

Maton, K. (2013). Knowledge and knowers. Towards a realist sociology of education. London: Routledge.

Matthews, D. (2006). Epistemic humility. In J. P. van Gigch (Ed.), Wisdom, knowledge, and management. New York, NY: Springer.

OECD. (2006). Are students ready for a technologyrich world? What PISA studies tell us. Paris: OECD Publishing.

OECD. (2010). PISA 2009 results: What students know and can do (Vol. I): Student performance in reading, mathematics and science. Paris: OECD Publishing.

OECD. (2014). PISA 2012 results: What students know and can do (Vol. I): Student performance in mathematics, reading and science. Paris: OECD Publishing.

OECD. (2016). PISA 2015 results (Vol. II): Policies and practices for successful schools. Paris: OECD Publishing.

Ottestad, G., \& Gudmundsdottir, G. B. (2018). ICT policy in primary and secondary education in Europe. In $\mathrm{J}$. Voogt, G. Knezek, R. Christensen, \& K.-W. Lai (Eds.), Handbook of information technology in primary and secondary education. Cham: Springer.

Pelgrum, W. J., \& Anderson, R. E. (1999). ICT and the emerging paradigm for life-long learning. Amsterdam: IEA.

Plomp, T., Anderson, R. E., Law, N., \& Quale, A. (Eds.). (2009). Cross national information and communication technology, policies and practices in education. Charlotte: Information Age Publishing. 
Poyntz, S. (2015). Conceptual futures: Thinking and the role of key concept models in media literacy education. Media Education Research Journal, 6(2), 63-79.

Sannino, A., \& Engeström, Y. (2017). Relational agency, double stimulation, and the object of activity: An intervention study in a primary school. In A. Edwards (Ed.), Working relationally in and across practices: A cultural-historical approach to collaboration (pp. 43-57). New York, NY: Cambridge University Press.

Scaradozzi, D., Sorbi, L., Pedale, A., Valzano, M., \& Vergine, C. (2015). Teaching robotics at the primary school: An innovative approach. Procedia-Social and Behavioral Sciences, 174, 3838-3846. https:// doi.org/10.1016/j.sbspro.2015.01.1122

Shapiro, L. (2007). The embodied cognition research programme. Philosophy Compass, 2(2), 338-346. https://doi.org/10.1111/j.1747-9991.2007.00064.x

Shapiro, R. (2015). Geopolitics of digital literacies: Accounting for myths and realities (PhD dissertation). Syracuse University, Syracuse.

Silseth, K. (2013). Constructing learning dialogically; learners, context, and resources. Exploring how students and teachers participate igame-based learning and digital storytelling in educational settings (PhD dissertation), University of Oslo, Oslo.

Stetsenko, A. (2017). The transformative mind: Expanding Vygotsky's approach to development and education. New York, NY: Cambridge University Press.

Strømme, T. A., \& Furberg, A. (2015). Exploring teacher intervention in the intersection of digital resources, peer collaboration, and instructional design. Science Education, 99(5), 837-862.

Säljö, R. (2010). Digital tools and challenges to institutional traditions of learning: Technologies, social memory and the performative nature of learning. Journal of Computer Assisted Learning, 26(1), 53-64.

Tømte, C. E. (2013). Educating teachers for the new millennium? Nordic Journal of Digital Literacy, 8(1/2), 74-88.

van Joolingen, W. R., de Jong, T., \& Dimitrakopoulou, A. (2007). Issues in computer supported inquiry learning in science. Journal of Computer Assisted Learning, 23, 111-119.

Virkkunen, J. (2006). Dilemmas in building shared transformative agency. @ctivités, 3(1), 43-66.

Vygotsky, L. S. (1978). Mind in society: The development of higher psychological processes. Cambridge, MA: Harvard University Press.

\section{About the Authors}

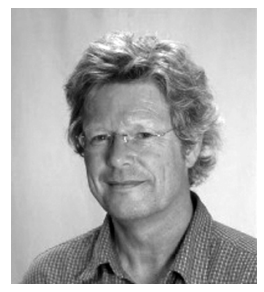

Andreas Lund is Professor at the Department of Teacher Education and School Research, University of Oslo. Lund's research involves teacher education, Computer-Support for Collaborative Learning, human interactions in technology-rich environments, sociocultural and activity theoretical perspectives on learning and didactics, as well as speech communities and communication change. Lund was the first Head of ProTed, Norway's first Center of Excellence in Education.

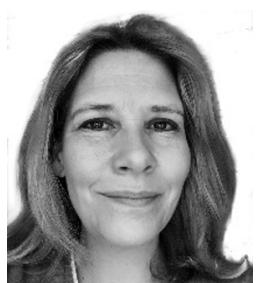

Anniken Furberg is Associate Professor at Department of Teacher Education and School Research, University of Oslo. Furberg's main academic interests relate to classroom studies focusing on students' learning processes in Computer-Supported Collaborative Learning and the role of support provided by teachers in technology-rich learning settings. This also involves an interest in teachers' professional digital competencies, and how teacher education programs can facilitate student teachers' development of professional digital competencies.

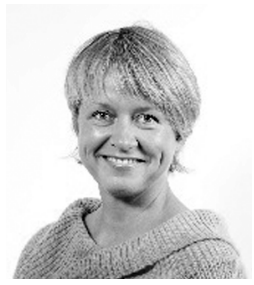

Greta Björk Gudmundsdottir is Associate Professor at the Department of Teacher Education and School Research, University of Oslo. Gudmundsdottir's work focuses on ICT in teaching and learning in schools as well as in teacher education. Gudmundsdottir's research on coherence in teacher education explores how teacher education can better integrate student teachers' theoretical knowledge of digital competence with their practical teaching experiences during practice placements. 